Elsevier required licence: (c) <2020>. This manuscript version is made available under the CC-BY-NC-ND 4.0 license http://creativecommons.org/licenses/by-nc-nd/4.0/

The definitive publisher version is available online at https://doi.org/10.1016/j.chemphyslip.2020.104952 


\section{Expansion of the structure-activity relationship of branched chain fatty acids: effect of unsaturation and branching group size on anticancer activity.}

Ritik Roy ${ }^{1}$, Ariane Roseblade ${ }^{1}$, and Tristan Rawling*.

School of Mathematical and Physical Sciences, Faculty of Science, University of Technology Sydney, Sydney, NSW, 2007, Australia.

${ }^{1}$ Co-first authors

*Correspondence: $\quad$ Dr Tristan Rawling, School of Mathematical and Physical Sciences, Faculty of Science, University of Technology Sydney, Ultimo, NSW 2007, Australia. Tel: (61-2)-9514-7956, Email: Tristan.Rawling@uts.edu.au

Key words: branched chain fatty acid, 13-methyltetradecanoic acid, breast cancer, MCF-7, structure activity relationship 


\section{ABSTRACT}

Branched chain fatty acids (BCFAs) are a class of fatty acid with promising anticancer activity. The BCFA 13-methyltetradecanoic acid (13-MTD) inhibits tumour growth in vivo without toxicity but efficacy is limited by moderate potency, a property shared by all known BCFAs. The mechanism of action of BCFAs has not been fully elucidated, and in the absence of a clearly defined target optimisation of BCFA potency must rely on structure-activity relationships. Our current understanding of the structural features that promote BCFA anticancer activity is limited by the low structural diversity of reported BCFAs. The aim of this study was to examine the effects of two new structural modifications- unsaturation and branching group size- on BCFA activity. Thus, homologous series of saturated and cis- $\Delta 9$ unsaturated BCFAs were synthesised bearing methyl, ethyl, propyl and butyl branching groups, and were screened in vitro for activity against three human cancer cell lines. Potencies of the new BCFAs were compared to 13-MTD and an unbranched monounstaurated fatty acid (MUFA) bearing a $c i s-\Delta 9$ double bond. The principal findings to emerge were that the anticancer activity of BCFAs was adversly affected by larger branching groups but significantly improved by incorporation of a cis- $\Delta 11$ double bond into the BCFA alkyl chain. This study provides new structure-activity relationship insights that may be used to develop BCFAs with improved potency and therapeutic potential. 


\section{Introduction}

Breast cancer is the second leading cause of cancer-relates deaths in women, and there is a critical need to develop novel anticancer drugs to treat cancers that are refractory to established anticancer agents. Accumulating evidence suggests that lipids and fatty acids possess anticancer actions that can be harnessed to develop new drugs to inhibit tumour growth, and drug design strategies to overcome their challenging physicochemical properties have yielded clinically approved drugs (Collins et al., 1993; Murray et al., 2014; Murray et al., 2015; Van \& Verheij, 2013). Thus, lipids and fatty acids are viable lead compounds for cancer drug development.

Branched chain fatty acids (BCFAs) are a naturally occurring class of fatty acids with anticancer actions. The widely studied BCFA, 13-methyltetradecanoic acid (13-MTD, Fig. 1), is an iso- $\mathrm{C}_{15}$ branched chain fatty acid that was first isolated from a fermented soy bean product marketed as a nutritional and therapeutic supplement. In cell-based studies 13-MTD inhibited proliferation and induced apoptosis in several human cancer cell lines, including breast (MCF7, SK-BR-3), bladder (T24, 5637), prostate (DU-145), colon (HCT-116), liver (SNU-423, LCID35), lymphatic (Jurkat, EL4) and pancreatic (BxPC-3) cancer with $\mathrm{IC}_{50}$ values ranging from $26-159 \mu \mathrm{M}$ (Cai et al., 2013; Lin et al., 2012; Shioiri et al., 1998; Wongtangtintharn et al., 2005; Wongtangtintharn et al., 2004; Yang et al., 2000). 13-MTD is well tolerated by mice and oral delivery of 13-MTD (35-70 mg/kg/day) inhibited tumour growth in mice carrying DU 145 , LCI-D35, and Jurkat xenografts (Cai et al., 2013; Yang et al., 2000). The naturally occurring anteiso- $\mathrm{C}_{15}$ analogue of 13-MTD, 12-methyltetradecanoic acid (12-MTA), has also been shown to inhibit proliferation of several cancer cell lines, including prostate (DU145, PC3), lung (H1299, A549) and breast cancer (MCF-7), with $\mathrm{IC}_{50}$ values ranging from $71-146 \mu \mathrm{M}$, and like 13-MTD, reduced tumour growth in vivo without any apparent toxicity (Murray et al., 2014; Wongtangtintharn et al., 2004; Wright et al, 2005; Yang et al., 2003). 
Although 13-MTD and 12-MTA possess promising in vivo activity, moderate potency limits their efficacy and therapeutic potential. Medicinal chemistry-based approaches to improve drug potency typically involve understanding the steric and electronic factors that govern the interaction of a drug with its cellular target. Several studies of 13-MTD have identified possible mechanisms of action such as disruption of mitochondrial integrity, membrane fluidity, and fatty acid biosynthesis (Cai et al., 2013; Lin et al., 2012; Wongtangtintharn et al., 2006; Wongtangtintharn et al., 2005; Yang et al., 2000), however the precise cellular target of 13-MTD remains unknown. In the absence of a defined target, a ligand-based approach to improve BCFA anticancer activity must be undertaken, which involves the development of a structure-activity relationship (SAR) that describes how drug activity is affected by structural modifications.

Some SAR insights on the BCFA scaffold have emerged. A series of $\mathrm{C}_{12-20}$ iso-BCFAs, which are structural analogues of 13-MTD but with elongated or contracted alkyl chains, were assess for activity against MCF-7 breast cancer cells. The iso- $\mathrm{C}_{16}$ BCFA was the most potent in the series and inhibited MCF-7 cell proliferation with an $\mathrm{IC}_{50}$ of $\sim 80 \mu \mathrm{M}$, and potency decreased with an increase or decrease in chain length $\left(\mathrm{IC}_{50}\right.$ concentrations from $\sim 150-300$ $\mu \mathrm{M})$ (Wongtangtintharn et al., 2004). Iso-BCFAs exhibit greater anticancer activity relative to their anteiso-counterparts. In a direct comparison, 13-MTD exerted greater anti-proliferative and pro-apoptotic effects than 12-MTA in MCF-7 cells (Vahmani et al., 2019). Similarly, Iso$\mathrm{C}_{17}$ inhibited MCF-7 cell proliferation with an $\mathrm{IC}_{50}$ of $\sim 190 \mu \mathrm{M}$, whereas the anteiso- $\mathrm{C}_{17}$ analogue only reduced cell growth to $\sim 80 \%$ at the highest concentration tested $(400 \mu \mathrm{M})$ (Vahmani et al., 2019; Wongtangtintharn et al., 2004). Methyl branching beyond the iso- and anteiso-positions, as well as multiple methyl branching groups, have also been explored, however cytotoxic activity against SK-BR-3 breast cancer cells remained modest $\left(\mathrm{IC}_{50} \sim 300\right.$ $350 \mu \mathrm{M})($ Oku \& Yanagita, 2009; Wongtangtintharn et al., 2006). 
The SAR for BCFA anticancer activity is limited by the lack of structural diversity in the BCFAs tested to date. All tested BCFAs possess methyl branching groups at various positions along saturated alkyl chains, and to our knowledge the effect of extended alkyl branching and unsaturation on anticancer activity has not been investigated. In this paper we report on the synthesis of a homologous series of saturated and unsaturated BCFAs, in which terminally branched methyl groups are replaced with ethyl, propyl and butyl moieties (Fig. 1). The anticancer activity of these new BCFAs were assessed against MCF-7, MDA-MB-231 and HeLa cancer cell lines and compared to $13-\mathrm{MTD}$, and the results were used to gain SAR insights that we anticipate will assist in the design of new and more potent BCFAs. 


\section{Material and Methods}

\subsection{General Chemistry}

11-Bromoundecanoic acid was purchased from Fluorochem (Hadfield, Derbyshire, UK). All other reagents and anhydrous solvents were purchased from Sigma Aldrich (Castle Hill, NSW, Australia). Reactions were monitored by thin-layer chromatography (TLC) using silica gel $60 \mathrm{~F}_{254}$ plates. TLC plates were visualised with UV light and potassium permanganate TLC stain. Reaction products were purified by dry column vacuum chromatography with Merck silica gel $60 \mathrm{H}$ as the stationary phase in a $70 \mathrm{~mm}$ (ID) x $60 \mathrm{~mm}$ (h) column. $12 \times 50 \mathrm{~mL}$ fractions were collected using gradient elutions of hexane:DCM. The first fraction was 100:0 and the percentage of DCM was increased by $5 \%$ increments to $50 \%$ DCM. ${ }^{1} \mathrm{H}$ and ${ }^{13} \mathrm{C}$ NMR spectra were recorded on an Agilent $500 \mathrm{MHz}$ NMR. Spectra were referenced internally to residual solvent $\left(\mathrm{CDCl}_{3} ;{ }^{1} \mathrm{H} \delta 7.26,{ }^{13} \mathrm{C} \delta 77.10\right.$. DMSO- $\left.d_{6} ;{ }^{1} \mathrm{H} \delta 2.49,{ }^{13} \mathrm{C} \delta 39.52\right)$. High resolution mass spectra (HRMS) were recorded on an Agilent Technologies 6510 Q-TOF LCMS.

Gas chromatography-mass spectrometry (GC-MS) was performed on a Shimadzu GCMS-QP2020 gas chromatograph-mass spectrometer fitted with an SH-Rxi-5Sil MS silica fused capillary column $(30.0 \mathrm{~m} \times 0.25 \mathrm{~mm} \times 0.25 \mu \mathrm{m})$. Automated injections were performed on a Shimadzu AOC-20i auto injector. The injection port temperature was $280{ }^{\circ} \mathrm{C}$ and $1.0 \mu \mathrm{L}$ injections were made in splitless mode with a purge time of $1 \mathrm{~min}$. Helium was used as a carrier gas, at a flow rate of $1.42 \mathrm{~mL} / \mathrm{min}$. The column temperature was as follows: initial temperature of $40{ }^{\circ} \mathrm{C}$ for $2 \mathrm{~min}$, then ramped at $6{ }^{\circ} \mathrm{C} / \mathrm{min}$ to $320^{\circ} \mathrm{C}$, and held for $1 \mathrm{~min}$. Eluted compounds were subjected to methane chemical ionisation and detection was made in full scan mode.

The purity of all test compounds was confirmed by absolute quantitative NMR (qNMR). Briefly, DMSO-d 6 was spiked with the internal calibrant (IC) 1,3,5-trioxane (99.5\%) to give a final IC concentration of $2.92 \mathrm{mg} / \mathrm{mL}$. Test compounds were accurately weighed on 
a 5-decimal place analytical balance, dissolved in $600 \mu \mathrm{L}$ of IC spiked DMSO- $\mathrm{d}_{6}$ and transferred to $5 \mathrm{~mm}$ NMR tubes. ${ }^{1} \mathrm{H}$ NMR spectra was recorded and the average integration of one proton from the IC and test compound was determined. The purity of the test compound (t) was then calculated using the following equation:

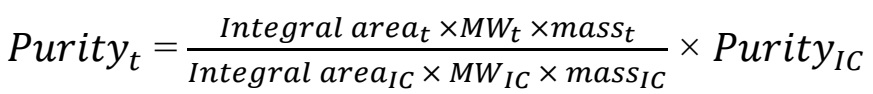

\subsection{Methyl 11-bromoundecanoate (2)}

To a mixture of $1(6.00 \mathrm{~g}, 22.63 \mathrm{mmol})$ in methanol $(300 \mathrm{~mL})$ was added $\mathrm{AcCl}(8.69 \mathrm{~g}, 113.13$ mmol). The resulting solution was left to stir at room temperature for $4 \mathrm{~h}$. Excess methanol was removed under pressure and the residue was dissolved in DCM $(80 \mathrm{~mL})$. The organic phase was washed with saturated $\mathrm{NaHCO}_{3}$ in water $(100 \mathrm{~mL})$, water $(100 \mathrm{~mL})$ and brine $(100$ $\mathrm{mL}$ ) and dried over $\mathrm{MgSO}_{4}$. The solution was concentrated in vacuo affording methyl ester 2 as a yellow oil (5.88 g, $93 \%)$ that was used without further purification. HRMS (ESI) $\mathrm{m} / \mathrm{z}$ $[\mathrm{M}+\mathrm{H}]^{+}$calcd for $\mathrm{C}_{12} \mathrm{H}_{23} \mathrm{O}_{2} \mathrm{Br} 279.0954$; found 279.0946. ${ }^{1} \mathrm{H}$ and ${ }^{13} \mathrm{C}$ NMR spectra were in agreement with previously reported data (Jana et al., 2018).

\section{3 (11-methoxy-11-oxoundecyl)(triphenyl)phosphonium bromide (3)}

Ester $2(5.88 \mathrm{~g}, 21.06 \mathrm{mmol})$ was left to stir with $\mathrm{PPh}_{3}(5.52 \mathrm{~g}, 21.06 \mathrm{mmol})$ at $140^{\circ} \mathrm{C}$ for 20 hours. The resulting mixture was dissolved in DCM $(5 \mathrm{~mL})$ and cold diethyl ether $(15 \mathrm{~mL})$ was added to form a precipitate. The solid was collected by vacuum filtration and washed with cold diethyl ether $(2 \times 15 \mathrm{~mL})$ and hexane $(3 \times 15 \mathrm{~mL})$. The product was dried in vacuo, affording 3 as a white solid $(10.41 \mathrm{~g}, 91 \%)$ that was used without further purification. $\mathrm{Mp}=111-113^{\circ} \mathrm{C}$. HRMS (ESI) $m / z[\mathrm{M}]^{+}$calcd for $\mathrm{C}_{30} \mathrm{H}_{38} \mathrm{O}_{2} \mathrm{P}$ 461.2598; found $461.2599 .{ }^{1} \mathrm{H}$ and ${ }^{13} \mathrm{C} \mathrm{NMR}$ spectra were in agreement with previously reported data (Dejarlais \& Emken, 1978). 


\subsection{General synthesis of the monounsaturated methyl esters $\mathbf{5 a - d}$}

To a suspension of $\mathbf{3}(1.500 \mathrm{~g}, 2.77 \mathrm{mmol})$ in anhydrous $\mathrm{THF}(10 \mathrm{~mL})$ at $0^{\circ} \mathrm{C}$ under a nitrogen atmosphere was added $\mathrm{NaN}(\mathrm{TMS})_{2}(1.0 \mathrm{M}$ in THF, $2.77 \mathrm{mmol})$. The resulting bright orange mixture was stirred for 20 minutes at room temperature. The reaction mixture was then cooled to $-78^{\circ} \mathrm{C}$, and the aldehyde $(\mathbf{4 a - d}, 1.85 \mathrm{mmol})$ in THF $(3 \mathrm{~mL})$ was added dropwise. The mixture was stirred for 30 minutes at $-78^{\circ} \mathrm{C}$ after which the reaction was allowed to warm to room temperature for two hours. After further stirring for two hours at room temperature the reaction was quenched with saturated aqueous $\mathrm{NH}_{4} \mathrm{Cl}(30 \mathrm{~mL})$ and extracted with EtOAc $(3 \times 50 \mathrm{~mL})$. The combined extracts were dried over $\mathrm{MgSO}_{4}$ and the EtOAc was removed in vacuo. The residue was purified on silica gel using a stepwise gradient elution with hexane:DCM (100:0 to 50:50) to yield the unsaturated methyl esters 5a-d.

\subsubsection{Methyl (Z)-13-methyltetradec-11-enoate (5a)}

Yellow oil, yield $=42 \% .{ }^{13} \mathrm{C}$ NMR $\left(125 \mathrm{MHz}, \mathrm{CDCl}_{3}\right) \delta 174.31,137.46,127.46,51.40,34.09$, $29.88,29.43,29.39,29.24,29.22,29.12,27.27,26.41,24.93,23.21 . Z: E$ ratio $=97.8: 2.2$. HRMS (ESI) $m / z$ [M+H] $]^{+}$calcd for $\mathrm{C}_{16} \mathrm{H}_{31} \mathrm{O}_{2} 255.2319$; found 255.2318. The ${ }^{1} \mathrm{H}$ spectrum was in agreement with previously reported data (Fogila and Vail, 1993).

\subsubsection{Methyl (Z)-13-ethylpentadec-11-enoate (5b)}

Yellow oil, yield $=75 \% .{ }^{1} \mathrm{H}$ NMR $\left(500 \mathrm{MHz}, \mathrm{CDCl}_{3}\right) \delta 5.39(\mathrm{dt}, J=10.5,2.5 \mathrm{~Hz}, 1 \mathrm{H}), 5.00$ (t, $J=7.5 \mathrm{~Hz}, 1 \mathrm{H}), 3.66(\mathrm{~s}, 3 \mathrm{H}), 2.30$ (t, $J=7.5 \mathrm{~Hz}, 2 \mathrm{H}), 2.16-2.06(\mathrm{~m}, 1 \mathrm{H}), 2.00$ (q, $J=7.5$ $\mathrm{Hz}, 2 \mathrm{H}), 1.61$ (quint, $J=7.5 \mathrm{~Hz}, 2 \mathrm{H}), 1.43-1.36(\mathrm{~m}, 2 \mathrm{H}), 1.35-1.24(\mathrm{~m}, 12 \mathrm{H}), 1.19-1.10(\mathrm{~m}$, 2H), $0.82(\mathrm{t}, J=7.5 \mathrm{~Hz}, 6 \mathrm{H}) .{ }^{13} \mathrm{C} \mathrm{NMR}\left(125 \mathrm{MHz}, \mathrm{CDCl}_{3}\right) \delta 174.32,134.43,130.04,51.42$, $40.62,34.10,29.88,29.44,29.40,29.30,29.22,29.13,28.30,27.68,24.94,11.86 . Z: E$ ratio $=$ 100.0 : 0.0. HRMS (ESI) $m / z[\mathrm{M}+\mathrm{H}]^{+}$calcd for $\mathrm{C}_{18} \mathrm{H}_{35} \mathrm{O}_{2}$ 283.2632; found 283.2634. 


\subsubsection{Methyl (Z)-13-propylhexadec-11-enoate (5c)}

Yellow oil, yield $=21 \% .{ }^{1} \mathrm{H}$ NMR $\left(500 \mathrm{MHz}, \mathrm{CDCl}_{3}\right) \delta 5.34(\mathrm{dt}, J=10.5,2.5 \mathrm{~Hz}, 1 \mathrm{H}), 5.01$ (t, $J=7.5 \mathrm{~Hz}, 1 \mathrm{H}), 3.66(\mathrm{~s}, 3 \mathrm{H}), 2.30(\mathrm{t}, J=7.5 \mathrm{~Hz}, 2 \mathrm{H}), 2.00(\mathrm{q}, J=7.5 \mathrm{~Hz}, 2 \mathrm{H}), 1.61$ (quint, $J=7.5 \mathrm{~Hz}, 2 \mathrm{H}), 1.34-1.25(\mathrm{~m}, 12 \mathrm{H}), 1.24-1.17(\mathrm{~m}, 2 \mathrm{H}), 1.16-1.08(\mathrm{~m}, 2 \mathrm{H}), 0.86(\mathrm{t}, J=7.5 \mathrm{~Hz}$ $6 \mathrm{H}) .{ }^{13} \mathrm{C} \mathrm{NMR}\left(125 \mathrm{MHz}, \mathrm{CDCl}_{3}\right) \delta 174.33,135.06,129.47,51.42,38.26,36.68,34.11,29.91$, $29.44,29.40,29.33,29.23,29.15,27.69,24.95,20.45,14.30 . Z: E$ ratio $=100.0: 0.0$. HRMS (ESI) $m / z[\mathrm{M}+\mathrm{H}]^{+}$calcd for $\mathrm{C}_{20} \mathrm{H}_{39} \mathrm{O}_{2}$ 311.2945; found 311.2947.

\subsubsection{Methyl (Z)-13-butylheptadec-11-enoate (5d)}

Yellow oil, yield $=43 \% .{ }^{1} \mathrm{H}$ NMR $\left(500 \mathrm{MHz}, \mathrm{CDCl}_{3}\right) \delta 5.34(\mathrm{dt}, J=10.5,2.5 \mathrm{~Hz}, 1 \mathrm{H}), 5.01$ (t, $J=7.5 \mathrm{~Hz}, 1 \mathrm{H}), 3.66(\mathrm{~s}, 3 \mathrm{H}), 2.30(\mathrm{t}, J=7.5 \mathrm{~Hz}, 2 \mathrm{H}), 2.28-2.21(\mathrm{~m}, 1 \mathrm{H}), 2.00(\mathrm{q}, J=7.5$ $\mathrm{Hz}, 2 \mathrm{H}), 1.61$ (quint, $J=7.5 \mathrm{~Hz}, 2 \mathrm{H}), 1.36-1.21(\mathrm{~m}, 20 \mathrm{H}), 1.20-1.09(\mathrm{~m}, 4 \mathrm{H}), 0.91-84(\mathrm{~m}, 6 \mathrm{H})$.

${ }^{13} \mathrm{C}$ NMR $\left(125 \mathrm{MHz}, \mathrm{CDCl}_{3}\right) \delta 174.32,135.18,129.44,51.42,37.08,35.68,34.11,29.90$, $29.62,29.47,29.41,29.34,29.24,29.15,27.70,24.95,22.92,14.12 . Z: E$ ratio $=99.7: 0.3$. HRMS (ESI) $m / z[\mathrm{M}+\mathrm{H}]^{+}$calcd for 339.3258; found 339.3255.

\subsubsection{Methyl (Z)-tetradec-11-enoate (5e)}

Yellow oil, yield: $86 \%$. ${ }^{1} \mathrm{H}$ NMR (500 MHz, $\left.\mathrm{CDCl}_{3}\right) \delta 5.39-5.31(\mathrm{~m}, 2 \mathrm{H}), 3.66(\mathrm{~s}, 3 \mathrm{H}), 2.30$ (t, $J=7.5 \mathrm{~Hz}, 2 \mathrm{H}), 2.06-1.99(\mathrm{~m}, 4 \mathrm{H}), 1.62$ (quint, $J=7 \mathrm{~Hz}, 2 \mathrm{H}), 1.37-1.25(\mathrm{~m}, 12 \mathrm{H}), 0.95$ (t, $J=7.5 \mathrm{~Hz}, 3 \mathrm{H}) .{ }^{13} \mathrm{C} \mathrm{NMR}\left(125 \mathrm{MHz}, \mathrm{CDCl}_{3}\right) \delta 175.83,131.34,128.85,51.38,33.98,29.75$, $29.46,29.35,29.23,29.22,29.06,27.02,24.68,20.55,14.48 . Z: E$ ratio $=100.0: 0.0$. HRMS (ESI) $m / z[\mathrm{M}+\mathrm{H}]^{+}$calcd for $\mathrm{C}_{15} \mathrm{H}_{28} \mathrm{O}_{2}$ 241.2162; found 241.2168. 
To a solution of the unsaturated methyl ester (5a-d, $0.20 \mathrm{mmol})$ in EtOH $(6 \mathrm{~mL})$ was added 1.5 $\mathrm{M} \mathrm{NaOH}(8 \mathrm{~mL})$. The reaction was heated to $40^{\circ} \mathrm{C}$ and stirred for four hours. The volume of the reaction mixture was reduced to $10 \mathrm{~mL}$ by rotary evaporation and the solution was adjusted to $\mathrm{pH} 1$ with $1.0 \mathrm{M} \mathrm{HCl}$. The solution was extracted with EtOAc $(3 \times 50 \mathrm{~mL})$ and the combined extracts were dried over $\mathrm{MgSO}_{4}$. The EtOAc was removed in vacuo to afford unsaturated fatty acids 6a-d in high purity ( $>95 \%)$ without further purification.

\subsection{1 (Z)-13-methyltetradec-11-enoic acid (6a)}

Yellow oil, yield $=93 \% .{ }^{1} \mathrm{H}$ NMR $\left(500 \mathrm{MHz}, \mathrm{CDCl}_{3}\right) \delta 5.25-5.15(\mathrm{~m}, 2 \mathrm{H}), 2.61-2.54(\mathrm{~m}, 2 \mathrm{H})$, $2.35(\mathrm{t}, J=7.5 \mathrm{~Hz}, 2 \mathrm{H}), 2.01(\mathrm{q}, J=7.5 \mathrm{~Hz}, 2 \mathrm{H}), 1.63$ (quint, $J=7.5 \mathrm{~Hz}, 2 \mathrm{H}), 1.37-1.23$ (m, 12H), $0.94(\mathrm{~d}, J=7.0 \mathrm{~Hz}, 6 \mathrm{H}) .{ }^{13} \mathrm{C} \mathrm{NMR}\left(125 \mathrm{MHz}, \mathrm{CDCl}_{3}\right) \delta 179.65,137.49,127.46,33.99$, 29.89, 29.44, 29.38, 29.24, 29.21, 29.04, 27.28, 26.42, 24.67, 23.22. FT-IR $v_{\max }$ (neat) 2923 (O-H stretch), 2853 (C-H stretch), 1707 (C=O stretch), 1463 (C-H bend), 1411 (O-H bend), $722(\mathrm{C}=\mathrm{C}$ bend $) \mathrm{cm}^{-1}$. HRMS (ESI) $m / z[\mathrm{M}+\mathrm{H}]^{+}$calcd for $\mathrm{C}_{15} \mathrm{H}_{29} \mathrm{O}_{2} 241.2162$; found 241.2163. $\mathrm{qNMR}$ purity $=95 \%$.

\subsection{2 (Z)-13-ethylpentadec-11-enoic acid (6b)}

Yellow oil, yield $=97 \% .{ }^{1} \mathrm{H}$ NMR $\left(500 \mathrm{MHz}, \mathrm{CDCl}_{3}\right) \delta 5.40(\mathrm{dt}, J=10.5,2.5 \mathrm{~Hz}, 1 \mathrm{H}), 5.01$ (t, $J=7.5 \mathrm{~Hz}, 1 \mathrm{H}), 2.35(\mathrm{t}, J=7.5 \mathrm{~Hz}, 2 \mathrm{H}), 2.16-2.07(\mathrm{~m}, 1 \mathrm{H}), 2.01(\mathrm{q}, J=7.5 \mathrm{~Hz}, 2 \mathrm{H}), 1.63$ (quint, $J=7.5 \mathrm{~Hz}, 2 \mathrm{H}), 1.44-1.37(\mathrm{~m}, 2 \mathrm{H}), 1.37-1.21(\mathrm{~m}, 12 \mathrm{H}), 1.20-1.09(\mathrm{~m}, 2 \mathrm{H}), 0.83(\mathrm{t}, J=$ $7.5 \mathrm{~Hz}, 6 \mathrm{H}) .{ }^{13} \mathrm{C} \mathrm{NMR}\left(125 \mathrm{MHz}, \mathrm{CDCl}_{3}\right) \delta 178.74,134.45,130.06,40.63,33.82,29.89,29.69$, $29.45,29.39,29.32,29.21,29.05,28.31,27.69,24.69 .22 .69,14.12,11.87$. FT-IR $v_{\max }$ (neat) 2922 (O-H stretch), 2853 (C-H stretch), 1708 (C=O stretch), 1456 (C-H bend), 1412 (O-H bend), $723\left(\mathrm{C}=\mathrm{C}\right.$ bend) $\mathrm{cm}^{-1}$. HRMS (ESI) $\mathrm{m} / z[\mathrm{M}+\mathrm{H}]^{+}$calcd for $\mathrm{C}_{17} \mathrm{H}_{33} \mathrm{O}_{2}$ 269.2475; found 269.2472. qNMR purity $=97 \%$. 


\subsection{3 (Z)-13-propylhexadec-11-enoic acid (6c)}

Yellow oil, yield $=90 \% .{ }^{1} \mathrm{H}$ NMR $\left(500 \mathrm{MHz}, \mathrm{CDCl}_{3}\right) \delta 5.34(\mathrm{dt}, J=10.5,2.5 \mathrm{~Hz}, 1 \mathrm{H}), 5.01$ (t, $J=7.5 \mathrm{~Hz}, 1 \mathrm{H}), 2.35(\mathrm{t}, J=7.5 \mathrm{~Hz}, 2 \mathrm{H}), 2.33-2.27(\mathrm{~m}, 1 \mathrm{H}), 2.01$ (q, $J=7.5 \mathrm{~Hz}, 2 \mathrm{H}), 1.63$ (quint, $J=7.5 \mathrm{~Hz}, 2 \mathrm{H}), 1.39-1.25(\mathrm{~m}, 16 \mathrm{H}), 1.24-1.19(\mathrm{~m}, 2 \mathrm{H}), 1.18-1.09(\mathrm{~m}, 2 \mathrm{H}), 0.86(\mathrm{t}, J=$ $7.5 \mathrm{~Hz}, 6 \mathrm{H}) .{ }^{13} \mathrm{C} \mathrm{NMR}\left(125 \mathrm{MHz}, \mathrm{CDCl}_{3}\right) \delta 179.17,135.08,129.47,38.28,36.69,33.89,29.92$, $29.70,29.62,29.51,29.45,29.40,29.34,29.22,29.16,29.07,28.95,27.71,24.69,20.46,14.32$. FT-IR $v_{\max }$ (neat) 2922 (O-H stretch), 2853 (C-H stretch), 1708 (C=O stretch), 1465 (C-H bend), 1413 (O-H bend), $722\left(\mathrm{C}=\mathrm{C}\right.$ bend) $\mathrm{cm}^{-1}$. HRMS (ESI) $\mathrm{m} / z[\mathrm{M}+\mathrm{H}]^{+}$calcd for $\mathrm{C}_{19} \mathrm{H}_{37} \mathrm{O}_{2}$ 297.2788; found 297.2786. qNMR purity $=97 \%$.

\subsection{4 (Z)-13-butylheptadec-11-enoic acid (6d)}

Yellow oil, yield $=81 \% .{ }^{1} \mathrm{H}$ NMR $\left(500 \mathrm{MHz}, \mathrm{CDCl}_{3}\right) \delta 5.35(\mathrm{dt}, J=10.5 \mathrm{~Hz}, 2.5 \mathrm{~Hz}, 1 \mathrm{H})$, $5.02(\mathrm{t}, J=7.5 \mathrm{~Hz}, 1 \mathrm{H}), 2.35(\mathrm{t}, J=7.5 \mathrm{~Hz}, 2 \mathrm{H}), 2.30-2.21(\mathrm{~m}, 1 \mathrm{H}), 2.01(\mathrm{q}, J=7.5 \mathrm{~Hz}, 2 \mathrm{H})$, 1.63 (quint, $J=7.5 \mathrm{~Hz}, 2 \mathrm{H}), 1.38-1.22(\mathrm{~m}, 20 \mathrm{H}), 1.21-1.09(\mathrm{~m}, 4 \mathrm{H}), 0.87(\mathrm{t}, J=7.5 \mathrm{~Hz}, 6 \mathrm{H})$. ${ }^{13} \mathrm{C}$ NMR $\left(125 \mathrm{MHz}, \mathrm{CDCl}_{3}\right) \delta 179.34,135.19,129.44,37.08,35.68,33.91,29.89,29.65$, $29.62,29.47,29.40,29.34,29.23,29.06,27.70,24.67,22.92,14.12$. FT-IR $v_{\max }$ (neat) 2922 (O-H stretch), 2853 (C-H stretch), 1708 (C=O stretch), 1465 (C-H bend), 1411 (O-H bend), $724(\mathrm{C}=\mathrm{C}$ bend $) \mathrm{cm}^{-1}$. HRMS (ESI) $m / z[\mathrm{M}+\mathrm{H}]^{+}$calcd for $\mathrm{C}_{21} \mathrm{H}_{41} \mathrm{O}_{2}$ 325.3101; found 325.3103 . qNMR purity $=96 \%$.

\subsection{5 (Z)-tetradec-11-enoic acid (6e)}

Yellow oil, yield: $85 \%$. HRMS (ESI) $m / z[\mathrm{M}+\mathrm{H}]^{+}$calcd for $\mathrm{C}_{14} \mathrm{H}_{26} \mathrm{O}_{2}$ 227.2006; found 227.2004. qNMR purity $=99 \% .{ }^{1} \mathrm{H}$ and ${ }^{13} \mathrm{C}$ NMR spectra were in agreement with previously reported data (Wube et al., 2011). 


\subsection{General synthesis of the saturated methyl esters 7 a-d}

To a mixture of the monounsaturated methyl ester (5a-d, $0.65 \mathrm{mmol})$ in EtOH $(10 \mathrm{~mL})$ under a hydrogen atmosphere was added $\mathrm{Pd} / \mathrm{C}(10 \mathrm{wt} \%$, $0.20 \mathrm{mmol})$. The suspension was stirred for 20 hours at room temperature, after which the mixture was filtered over celite and washed with EtOH $(2 \times 25 \mathrm{~mL})$. The EtOH was removed in vacuo and the residue was purified on silica gel with a stepwise gradient elution with hexane:DCM (100:0 to 50:50) to yield 7a-d.

\subsubsection{Methyl 13-methyltetradecanoate (7a)}

Yellow oil, yield $=87 \% .{ }^{1} \mathrm{H}$ NMR $\left(500 \mathrm{MHz}, \mathrm{CDCl}_{3}\right) \delta 3.66(\mathrm{~s}, 3 \mathrm{H}), 2.30(\mathrm{t}, J=7.5 \mathrm{~Hz}, 2 \mathrm{H})$, 1.61 (quint, $J=7.5 \mathrm{~Hz}, 2 \mathrm{H}), 1.58-1.44(\mathrm{~m}, 1 \mathrm{H}), 1.36-1.25(\mathrm{~m}, 16 \mathrm{H}), 1.17-1.12(\mathrm{~m}, 2 \mathrm{H}), 0.85$ $(\mathrm{d}, J=7.5 \mathrm{~Hz}, 6 \mathrm{H}) .{ }^{13} \mathrm{C} \mathrm{NMR}\left(125 \mathrm{MHz}, \mathrm{CDCl}_{3}\right) \delta 174.34,51.42,34.12,29.92,29.69,29.63$, 29.58, 29.44, 29.25, 29.14, 27.96, 27.40, 24.95, 22.65. HRMS (ESI) $m / z[\mathrm{M}+\mathrm{H}]^{+}$calcd for $\mathrm{C}_{16} \mathrm{H}_{33} \mathrm{O}_{2} 252.2475$; found 252.2478.

\subsubsection{Methyl 13-ethylpentadecanoate (7b)}

Yellow oil, yield $=68 \% .{ }^{1} \mathrm{H}$ NMR $\left(500 \mathrm{MHz} \mathrm{CDCl}_{3}\right) \delta 3.67(\mathrm{~s}, 3 \mathrm{H}), 2.30(\mathrm{t}, J=7.5 \mathrm{~Hz}, 2 \mathrm{H})$, 1.61 (quint, $J=7.5 \mathrm{~Hz}, 2 \mathrm{H}), 1.35-1.19(\mathrm{~m}, 21 \mathrm{H}), 1.18-1.11(\mathrm{~m}, 2 \mathrm{H}), 0.83(\mathrm{t}, J=7.5 \mathrm{~Hz}, 6 \mathrm{H})$. ${ }^{13} \mathrm{C}$ NMR $\left(125 \mathrm{MHz}, \mathrm{CDCl}_{3}\right) \delta 174.34,51.41,40.36,34.11,32.75,30.13,29.69,29.64,29.59$, 29.44, 29.25, 29.14, 26.76, 25.43, 24.95, 10.91. HRMS (ESI) $\mathrm{m} / z[\mathrm{M}+\mathrm{H}]^{+}$calcd for $\mathrm{C}_{18} \mathrm{H}_{37} \mathrm{O}_{2}$ 285.2788; found 285.2787.

\subsubsection{Methyl 13-propylhexadecanoate (7c)}

Yellow oil, yield $=83 \% .{ }^{1} \mathrm{H}$ NMR $\left(500 \mathrm{MHz}, \mathrm{CDCl}_{3}\right) \delta 3.66(\mathrm{~s}, 3 \mathrm{H}), 2.30(\mathrm{t}, J=7.5 \mathrm{~Hz}, 2 \mathrm{H})$, 1.61 (quint, $J=7.5 \mathrm{~Hz}, 2 \mathrm{H}), 1.28-1.15(\mathrm{~m}, 27 \mathrm{H}), 0.87(\mathrm{t}, J=7.5 \mathrm{~Hz}, 6 \mathrm{H}) .{ }^{13} \mathrm{C} \mathrm{NMR}(125 \mathrm{MHz}$, 
$\left.\mathrm{CDCl}_{3}\right) \delta 174.34,51.42,36.94,36.10,34.12,33.67,30.15,29.69,29.65,29.59,29.44,29.25$, 29.15, 26.67, 24.95, 19.79, 14.54. HRMS (ESI) $m / z[\mathrm{M}+\mathrm{H}]^{+}$calcd for $\mathrm{C}_{20} \mathrm{H}_{41} \mathrm{O}_{2}$ 313.3101; found 313.3103 .

\subsubsection{Methyl 13-butylheptadecanoate (7d)}

Yellow oil, yield $=44 \% .{ }^{1} \mathrm{H}$ NMR $\left(500 \mathrm{MHz}, \mathrm{CDCl}_{3}\right) \delta 3.66(\mathrm{~s}, 3 \mathrm{H}), 2.30(\mathrm{t}, J=7.5 \mathrm{~Hz}, 2 \mathrm{H})$, 1.61 (quint, $J=7.5 \mathrm{~Hz}, 2 \mathrm{H}), 1.33-1.15(\mathrm{~m}, 31 \mathrm{H}), 0.89(\mathrm{t}, J=7.5 \mathrm{~Hz}, 6 \mathrm{H}) .{ }^{13} \mathrm{C} \mathrm{NMR}(125 \mathrm{MHz}$, $\left.\mathrm{CDCl}_{3}\right) \delta 174.32,51.41,37.34,33.70,33.38,30.14,29.69,29.65,29.59,29.44,29.25,29.15$, 28.96, 26.70, 24.95, 23.16, 14.16. HRMS (ESI) $m / z[\mathrm{M}+\mathrm{H}]^{+}$calcd for $\mathrm{C}_{22} \mathrm{H}_{45} \mathrm{O}_{2}$ 341.3414; found 341.3415 .

\subsection{General procedure for synthesis of saturated branched fatty acids $8 \boldsymbol{b}-\boldsymbol{d}$}

To a mixture of the saturated methyl ester (7a-d, $0.20 \mathrm{mmol})$ in EtOH $(6 \mathrm{~mL})$ was added 1.5 $\mathrm{M} \mathrm{NaOH}(8 \mathrm{~mL})$. The reaction was heated to $40^{\circ} \mathrm{C}$ and stirred for four hours. The volume of the reaction mixture was reduced to $10 \mathrm{~mL}$ by rotary evaporation and the solution was adjusted to $\mathrm{pH} 1$ with $1.0 \mathrm{M} \mathrm{HCl}$. The white solid was extracted with EtOAc $(3 \times 50 \mathrm{~mL})$ and the combined extracts were dried over $\mathrm{MgSO}_{4}$. EtOAc was removed in vacuo to afford 13-MTD and $\mathbf{8 b - d}$ in high purity $(>95 \%)$ without further purification.

\subsubsection{3-methyltetradecanoic acid (13-MTD)}

White solid, yield $=89 \% . \mathrm{Mp}=47-49^{\circ} \mathrm{C}$ (lit. $\mathrm{Mp}=46.5-47{ }^{\circ} \mathrm{C}$ ) (Shioiri et al., 1998). FT-IR, HRMS, ${ }^{1} \mathrm{H}$ and ${ }^{13} \mathrm{C}$ NMR spectra were in agreement with previously reported data (Khan et al., 2018). qNMR purity $=98 \%$.

\subsubsection{3-ethylpentadecanoic acid (8b)}


Yellow oil, yield $=96 \% .{ }^{1} \mathrm{H}$ NMR $\left(500 \mathrm{MHz}, \mathrm{CDCl}_{3}\right) \delta 2.35(\mathrm{t}, J=7.5 \mathrm{~Hz}, 2 \mathrm{H}), 1.63$ (quint, $J$ $=7.5 \mathrm{~Hz}, 2 \mathrm{H}), 1.37-1.20(\mathrm{~m}, 21 \mathrm{H}), 1.19-1.11(\mathrm{~m}, 2 \mathrm{H}), 0.83(\mathrm{t}, J=7.5 \mathrm{~Hz}, 6 \mathrm{H}) .{ }^{13} \mathrm{C} \mathrm{NMR}(125$ $\left.\mathrm{MHz}, \mathrm{CDCl}_{3}\right) \delta 178.57,40.38,33.79,32.76,30.13,29.70,29.65,29.59,29.43,29.24,29.06$, 26.77, 25.44, 24.69. FT-IR $v_{\max }$ (neat) 2922 (O-H stretch), 2853 (C-H stretch), 1708 (C=O stretch), 1460 (C-H bend), $1412\left(\mathrm{O}-\mathrm{H}\right.$ bend) $\mathrm{cm}^{-1}$. HRMS (ESI) $\mathrm{m} / z[\mathrm{M}+\mathrm{H}]^{+}$calcd for $\mathrm{C}_{17} \mathrm{H}_{35} \mathrm{O}_{2} 271.2632$; found 271.2635. qNMR purity $=96 \%$.

\subsubsection{Characterization of 13-propylhexadecanoic acid (8c)}

Yellow oil, yield $=96 \% .{ }^{1} \mathrm{H}$ NMR $\left(500 \mathrm{MHz}, \mathrm{CDCl}_{3}\right) \delta 2.35(\mathrm{t}, J=7.5 \mathrm{~Hz}, 2 \mathrm{H}), 1.63$ (quint, $J$ $=7.5 \mathrm{~Hz}, 2 \mathrm{H}), 1.40-1.17(\mathrm{~m}, 27 \mathrm{H}), 0.87(\mathrm{t}, J=7.5 \mathrm{~Hz}, 6 \mathrm{H}) .{ }^{13} \mathrm{C} \mathrm{NMR}\left(125 \mathrm{MHz}, \mathrm{CDCl}_{3}\right) \delta$ $1.78 .73,36.94,36.10,33.81,33.67,30.14,29.69,29.65,29.61,29.58,29.50,29.42,29.35$, 29.23, 29.15, 29.06, 29.67, 24.69, 19.80, 14.54. FT-IR $v_{\max }$ (neat) 2923 (O-H stretch), 2853 (C$\mathrm{H}$ stretch), 1710 (C=O stretch), 1465 (C-H bend), 1418 (O-H bend) $\mathrm{cm}^{-1}$. HRMS (ESI) $\mathrm{m} / z$ $[\mathrm{M}+\mathrm{H}]^{+}$calcd for $\mathrm{C}_{19} \mathrm{H}_{39} \mathrm{O}_{2} 299.2945$; found 299.2946. qNMR purity $=97 \%$.

\subsubsection{Characterization of 13-butylheptadecanoic acid (8d)}

Yellow oil, yield $=89 \% .{ }^{1} \mathrm{H}$ NMR $\left(500 \mathrm{MHz}, \mathrm{CDCl}_{3}\right) \delta 2.35(\mathrm{t}, J=7.5 \mathrm{~Hz}, 2 \mathrm{H}), 1.63$ (quint, $J$ $=7.5 \mathrm{~Hz}, 2 \mathrm{H}), 1.41-1.17(\mathrm{~m}, 31 \mathrm{H}), 0.88(\mathrm{t}, J=7.5 \mathrm{~Hz}, 6 \mathrm{H}) .{ }^{13} \mathrm{C} \mathrm{NMR}\left(125 \mathrm{MHz}, \mathrm{CDCl}_{3}\right) \delta$ $178.77,37.35,33.81,33.70,33.38,30.14,29.69,29.65,29.58,29.43,29.32,29.05,28.96$, 26.70, 24.68, 23.16, 14.17. FT-IR $v_{\max }$ (neat) 2921 (O-H stretch), 2852 (C-H stretch), 1709 $\left(\mathrm{C}=\mathrm{O}\right.$ stretch), 1465 (C-H bend), $1412\left(\mathrm{O}-\mathrm{H}\right.$ bend) $\mathrm{cm}^{-1}$. HRMS (ESI) $\mathrm{m} / z[\mathrm{M}+\mathrm{H}]^{+}$calcd for $\mathrm{C}_{21} \mathrm{H}_{43} \mathrm{O}_{2}$ 327.3258; found 327.3256. qNMR purity $=96 \%$. 
Fetal bovine serum and trypsin/EDTA were purchased from (Invitrogen, Life Technologies, Victoria, Australia). Dulbecco's Modified Eagle Medium (DMEM), penicillin and streptomycin, phosphate-buffered saline (PBS), DMSO and general biochemicals were purchased from Sigma-Aldrich (Castle Hill, NSW, Australia). Human tumour cell lines were obtained from ATCC (Manassas, VA) and were grown at $37^{\circ} \mathrm{C}$ in a humidified atmosphere of $5 \% \mathrm{CO}_{2}$ in air in DMEM supplemented with $10 \%$ fetal bovine serum and $1 \%$ penicillin/streptomycin. Confluent cells (80-90\%) were harvested using Trypsin/EDTA after washing in PBS.

\subsection{Cell viability assay}

The anticancer activity of the synthesized compounds was determined using the MTS assay. Cells were seeded in 96 -well plates $\left(5 \times 10^{3}\right.$ cells per well), $24 \mathrm{~h}$ later serum was removed and cells were treated with various concentrations of the test compounds, in DMSO (final concentration $0.1 \%$ ), for $48 \mathrm{~h}$. Control cells received serum-free DMEM and DMSO at $0.1 \%$. Cell viability was determined using the CellTiter 96® AQueous One Solution Cell Proliferation Assay (Promega, USA) according to the manufacturer's recommendation. $\mathrm{IC}_{50}$ values were defined as the drug concentration that prevented cell growth of more than $50 \%$ (relative to the vehicle control) and were determined using nonlinear regression analysis with Prism 7.0 (GraphPad Software, CA, USA).

\subsection{Statistical analysis}

For in vitro assays, data were analysed using one-way analysis of variance (ANOVA) followed by Tukey's post hoc analysis. $\mathrm{P}<0.05$ were accepted as being statistically significant. All statistical analyses were performed using GraphPad Prism version 7.0 (GraphPad Software, CA, USA). The results are expressed as the means \pm SEM unless otherwise specified. 


\section{Results}

\subsection{Synthesis}

Saturated (13-MTD and 8b-d) and unsaturated (6a-d) BCFAs were synthesised as shown in Scheme 1. In the first step the carboxylic acid group in bromo fatty acid $\mathbf{1}$ was esterprotected using acetyl chloride and methanol. Under these mild reaction conditions acetyl chloride generates $\mathrm{HCl}$ in situ, which catalyses the esterification reaction. Methyl ester $\mathbf{2}$ was then reacted with triphenyl phosphine in a solvent-free melt to generate triphenylphosphonium bromide 3, which was then used in Wittig reactions with commercially available aldehydes 4ad to yield unsaturated branched fatty acid esters 5a-d with cis-double bonds in the $\Delta 11$ positions. To produce the desired cis-olefins the Wittig reactions were conducted in THF at $78^{\circ} \mathrm{C}$ with sodium bis(trimethylsilyl)amide as the base. These reaction conditions were chosen because they have been shown to favour formation of cis-olefins $(Z: E$ ratio $\geq 97: 3)$ (Ainai et al., 2003; Ito et al, 2006; Rawling et al., 2010). To confirm that the Wittig reactions proceeded with the desired selectivity, the $Z: E$ ratio of 5a-d was determined by GC-MS. The gaschromatograms of these compounds contained two peaks with identical mass spectra. Based on the elution order (Aro et al., 1998; Rawling et al., 2010), the first compounds to elute were identified as the trans-isomers ( $\mathrm{Rt} \sim 31.88 \mathrm{~min}$ ), which were baseline separated from the cisisomers $(\mathrm{Rt} \sim 31.98 \mathrm{~min})$. The peak areas were then used to calculate the $Z: E$ ratio, which in all cases exceed 97:3.

Olefins 5a-d were then divided into two sets of aliquots, and alkaline hydrolysis of the ester groups in one of the sets afforded unsaturated BCFAs 6a-d (Fig. 1). The double bonds in the remaining 5a-d aliquots were reduced with palladium and hydrogen to give saturated BCFA esters 7a-d. Finally, removal of the ester protecting groups yielded BCFAs 13-MTD and 8b-d. 


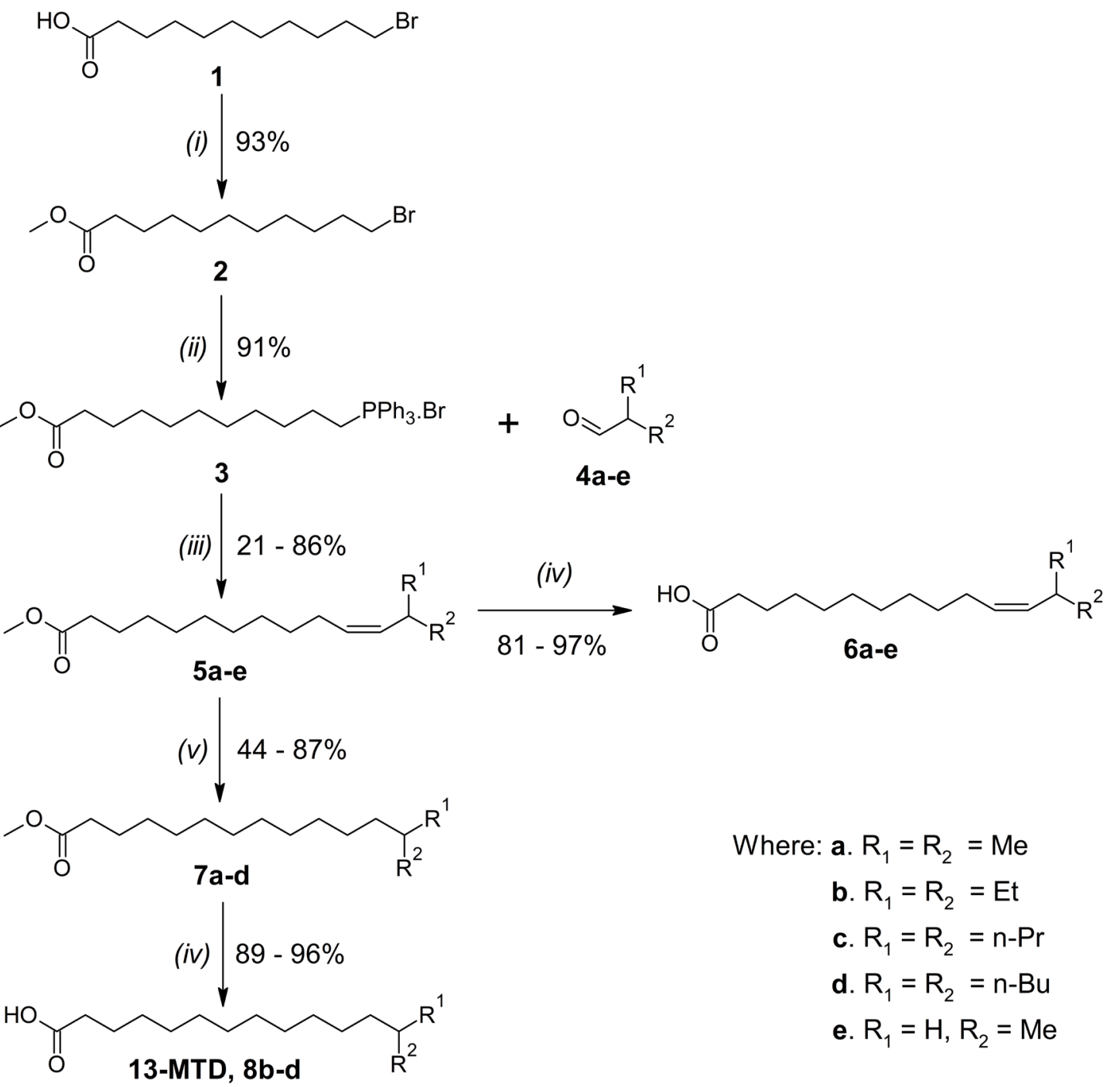

Scheme 1. Synthesis of the fatty acids 13-MTD 8b-d and 6a-e. Reagents and conditions ( $i$ ) AcCl, methanol, rt, 4 hours; (ii) $\mathrm{PPh}_{3}, 140{ }^{\circ} \mathrm{C}, 20$ hours; (iii) NaN(TMS)2, THF, $-78{ }^{\circ} \mathrm{C}$ to rt, 2 hours; (iv) 1.5M NaOH, ethanol, $40{ }^{\circ} \mathrm{C}$, 4 hours; (v) $\mathrm{Pd} / \mathrm{C}$, hydrogen, rt, 20 hours.

To assess the role of the methyl branching group and cis- $\Delta 11$ double bond in the anticancer activity of $\mathbf{6 a}$, we also prepared the monounsaturated fatty acid (MUFA) 6e, which is the straight chain analogue of $\mathbf{6 a}$. 6e was synthesised following the synthetic procedure outlined in Scheme 1. The Wittig reaction of phosphonium bromide $\mathbf{3}$ and straight chain aldehyde $4 \mathbf{e}$ affording the ester protect MUFA 5e with a cis- $\Delta 11$ double bond (Z:E ratio 
confirmed by GC-MS analysis). Base-catalysed hydrolysis of the 5e with sodium hydroxide provided 6e in high purity.
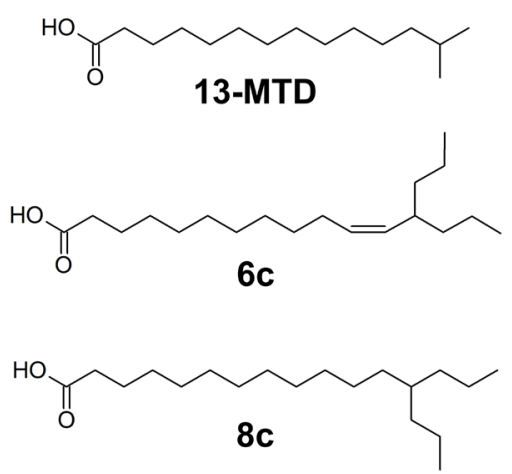

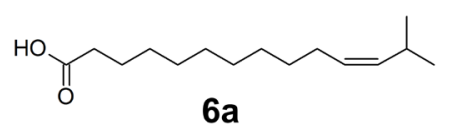

6a
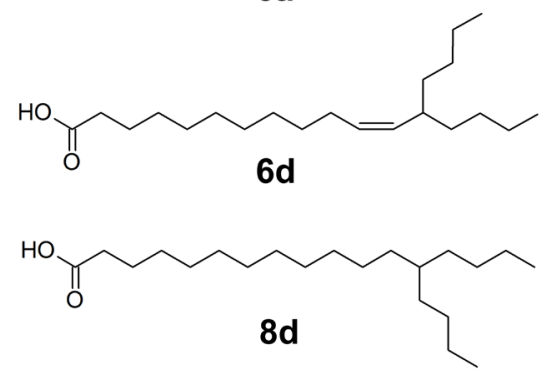
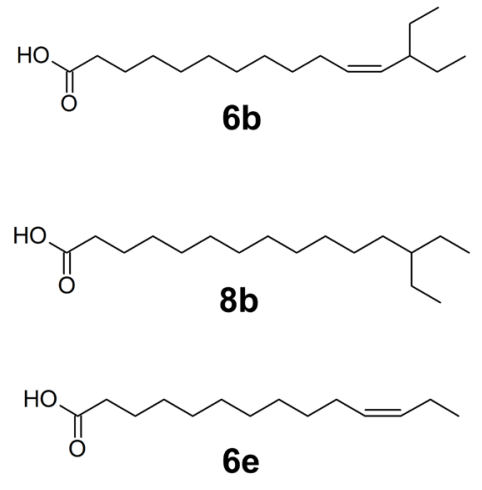

Fig. 1. Chemical structures of branched chain fatty acids used in this study.

\subsection{Cell culture conditions}

Prior to testing the all synthetic BCFAs against the full panel of cancer cell lines, we first developed assay conditions using 13-MTD, which is reported to reduce MCF-7 cell viability with $\mathrm{IC}_{50}$ concentrations of $10.03 \mu \mathrm{g} / \mathrm{ml}(\sim 41 \mu \mathrm{M})$ and $\sim 150 \mu \mathrm{M}$ in media containing 10\% fetal bovine serum (FBS) (Wongtangtintharn et al., 2004; Yang et al., 2000). In our hands, 13-MTD failed to affect MCF-7 cell viability at concentrations up to $500 \mu \mathrm{M}$ after 72 hours under these conditions. The same result was found with 13-MTD synthesised by us or purchased commercially. One important difference between our assay conditions and those used for 13-MTD, and indeed all other previously reported anticancer BFCAs, was our choice of DMSO as the drug delivery vehicle rather than Tween 80 (Cai et al., 2013; Lin et al., 2012; Shioiri et al., 1998; Wongtangtintharn et al., 2006; Wongtangtintharn et al., 2005; Wongtangtintharn et al., 2004; Yang et al., 2000). Tween 80 has been shown to potentiate the in vitro effects of some anticancer agents by permeabilising the cell membrane (Riehm and Biedler, 1972), and it is possible Tween 80 also potentiates BFCA anticancer activity in vitro. 
It is important to note that these observations do not invalidate the anticancer actions of 13MTD and other BCFAs, as indeed 13-MTD is active in vivo (Yang et al., 2000), however they do indicate that Tween 80 is not an ideal vehicle for in vitro anticancer assays.

We next attempted cell viability assays with DMSO as vehicle but in serum free media (SFM), as SFM has been used previously in assessing the anticancer activity of the BCFA 12methyltetradecanoic acid (Yang et al., 2003). In SFM we found that 13-MTD significantly reduced MCF-7 cell viability at concentrations $\geq 100 \mu \mathrm{M}$ (Fig 2a). To confirm that the cells were viable and proliferative SFM we conducted cell counts from the time of serum withdrawal to the end of the 48 hour treatment period. We found that MCF-7 cell number increased 1.5 fold over the treatment period. Similarly, the other two cell lines used in this study, MDA-MB231 and HeLa cells, grew 1.9 fold and 2.2 fold, respectively in SFM over 48 hours. Thus, all cell viability assays were performed in SFM for 48 hours with DMSO as delivery vehicle.

\subsection{In vitro anticancer activity}

The in vitro anticancer activities of the test fatty acids were first assessed against MCF7 cells. Dose-response curves were constructed (Fig 2) and $\mathrm{IC}_{50}$ concentrations were determined (Table 1). We also calculated Hill slopes (HS) and maximum effects ( $\left.E_{\max }\right)$ for each compound as these metrics can provide mechanistic information (Fallahi-Sichani et al., 2013).

In MCF-7 cells, 13-MTD was the most potent in the series of saturated BCFAs (13MTD, 8b-d) and reduced MCF-7 viability with an $\mathrm{IC}_{50}$ of $135 \pm 13 \mu \mathrm{M}$ (Table 1, Fig. 2a). IC $\mathrm{I}_{50}$ concentrations for the remaining saturated BCFAs were not able to be calculated due to limitations in the solubilities of these compounds at concentrations greater than $900 \mu \mathrm{M}$. From the dose-response curves obtained (Fig. 2b), the ethyl-branched analogue $\mathbf{8 b}$ displayed modest activity and was able to reduce MCF-7 cellular viability to $49 \pm 7 \%$ at $900 \mu \mathrm{M}$. Propyl- 
branched BCFA $8 \mathrm{c}$ only affected cellular viability at $900 \mu \mathrm{M}(76 \pm 4 \%)$, and the butyl-branched analogue $\mathbf{8 d}$ did not affect cellular viability at any of the test concentrations.

Unlike the saturated BCFAs $\mathbf{8 b}-\mathbf{d}$, all of the unsaturated BCFA's 6a-d were active against MCF-7 cells. Although 6a-d reduced MCF-7 viability with similar $\mathrm{IC}_{50}$ values, the shapes of the dose-response curves revealed differences between these compounds (Fig. 2c). Methyl, ethyl and propyl branched compounds 6a-c displayed relatively steep dose-response curves with Hill slopes $(H S)>2.8$ and maximum effect $\left(E_{\max }\right)$ values of 0 , reflecting the ability of 6a-c to completely abolish MCF-7 cell viability (Table 1). In contrast, the dose-response curve of the butyl-branched analogue $\mathbf{6 d}$ was shallow (HS = -1.6) and the cell viability did not drop below $32 \%$ as the concentration of $\mathbf{6 d}$ was increased from $150-450 \mu \mathrm{M}\left(\mathrm{E}_{\max }=0.3\right)$. 
Table 1. IC 50 concentrations, Hill Slopes (HS) and maximum effect ( $\left.E_{\max }\right)$ of fatty acids against the MCF7, MDA-MB-231 and HeLa cancer cell lines ${ }^{\mathrm{a}}$

MCF-7 MDA-MB-231

HeLa

\begin{tabular}{cccccccccc}
\hline $\begin{array}{c}\text { Fatty } \\
\text { Acid }\end{array}$ & $\begin{array}{c}\mathbf{I C}_{\mathbf{5 0}} \\
{[\boldsymbol{\mu M}]}\end{array}$ & $\mathbf{H S}$ & $\mathbf{E}_{\mathbf{m a x}}$ & $\begin{array}{c}\mathbf{I C}_{\mathbf{5 0}} \\
{[\boldsymbol{\mu M}]}\end{array}$ & $\mathbf{H S}$ & $\mathbf{E}_{\mathbf{m a x}}$ & $\begin{array}{c}\mathbf{I C}_{\mathbf{5 0}} \\
{[\boldsymbol{\mu M}]}\end{array}$ & $\mathbf{H S}$ & $\mathbf{E}_{\mathbf{m a x}}$ \\
\hline $13-\mathrm{MTD}$ & $135 \pm 13$ & -3.1 & 0.0 & Inactive $^{\mathrm{c}}$ & - & - & $>900$ & - & - \\
$\mathbf{8 b}$ & $>750$ & - & - & Inactive $^{\mathrm{c}}$ & - & - & $>900$ & - & - \\
$\mathbf{8 c}$ & $>900$ & - & - & Inactive $^{\mathrm{c}}$ & - & - & $>900$ & - & - \\
$\mathbf{8 d}$ & $>900$ & - & - & Inactive $^{\mathrm{c}}$ & - & - & $>900$ & - & - \\
$\mathbf{6 a}$ & $49.4 \pm 4.8$ & -6.4 & 0.0 & $534 \pm 39$ & -2.6 & 0.0 & $80.7 \pm 6.1$ & -1.5 & 0.0 \\
$\mathbf{6 b}$ & $58.9 \pm 9.2$ & -3.2 & 0.0 & Inactive $^{\mathrm{c}}$ & - & - & $>900$ & - & - \\
$\mathbf{6 c}$ & $51.8 \pm 6.1$ & -2.8 & 0.0 & Inactive $^{\mathrm{c}}$ & - & - & $>900$ & - & - \\
$\mathbf{6 d}$ & $47.6 \pm 3.1$ & -1.6 & 0.3 & Inactive $^{\mathrm{c}}$ & - & - & $>900$ & - & - \\
$\mathbf{6 e}$ & $86.4 \pm 9.3$ & -2.3 & 0.0 & $158 \pm 42$ & -2.2 & $\mathrm{~N} / \mathrm{A}^{\mathrm{b}}$ & $119 \pm 13$ & -1.2 & N/A \\
\hline
\end{tabular}

${ }^{a}$ Cell viability was measured using the MTS assay after $48 \mathrm{~h}$ of treatment.

${ }^{b}$ N/A: not applicable. $E_{\max }$ values for $6 \mathbf{e}$ in these cell lines could not be calculated because $\mathbf{6 e}$ was not soluble in cell media at concentration above $200 \mu \mathrm{M}$.

${ }^{\mathrm{c}}$ No effect on cell viability at concentrations up to $900 \mu \mathrm{M}$. 
A

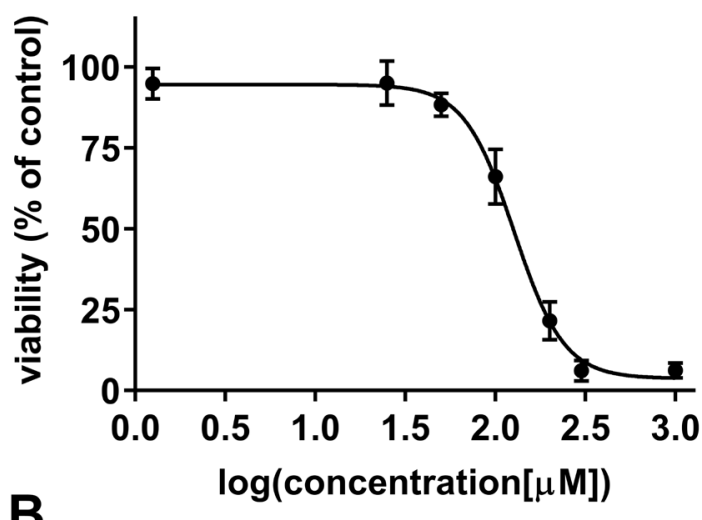

B
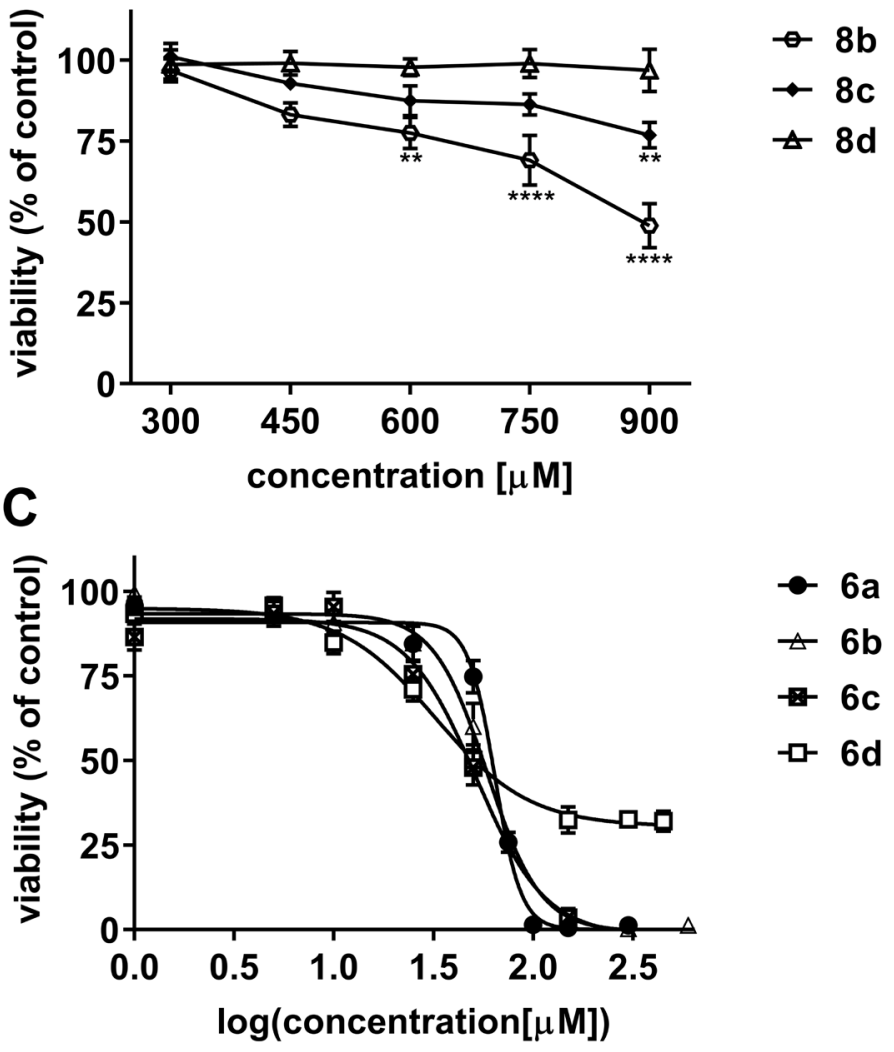

Fig. 2. Dose-response curves showing the effects of synthetic BCFAs on the viability of MCF7 breast cancer cells after $48 \mathrm{~h}$ treatment. A) 13-MTD, B) saturated BCFAs 8b-d, C) unsaturated BCFAs 6a-d. Data represents the mean \pm SEM of at least 3 independent experiments. ${ }^{* *} \mathrm{P}<0.01, * * * * \mathrm{P}<0.0001$, comparison of the indicated compound to the vehicle control. 
We also assessed the anticancer activity of the BCFAs against a wider panel of cancer cell lines (Table 1 and Fig. 3). In HeLa cervical cancer cells the unsaturated and methyl branched BCFA $6 \mathbf{a}$ was the most active in the series and reduced cell viability with an $\mathrm{IC}_{50}$ of $80.7 \pm 6.1 \mu \mathrm{M}$. All remaining BCFAs including 13-MTD were much less active that $6 \mathbf{a}$ and were only able to reduce cell viability to $70-90 \%$ of control at $900 \mu \mathrm{M}$ (Fig S1 and Table S1 in Supplementary Material).

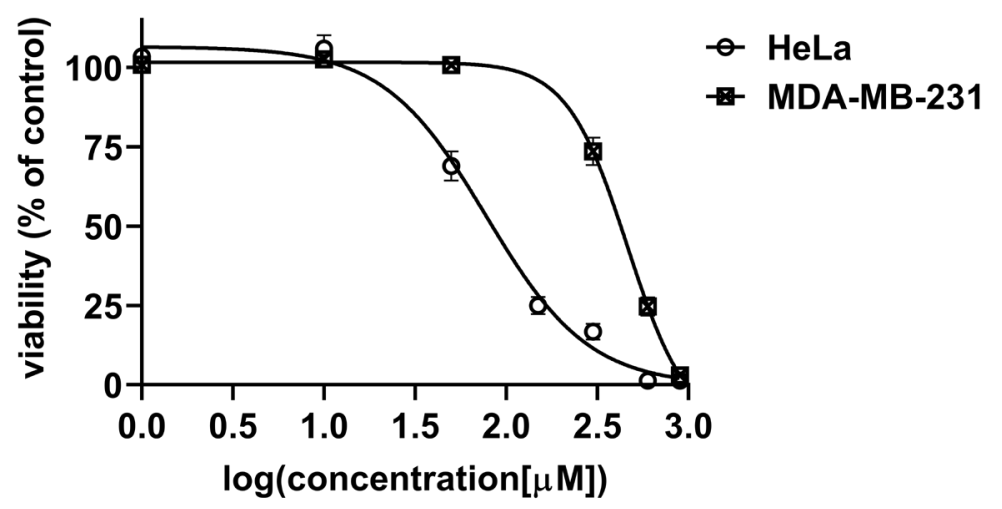

Fig. 3. Dose-response curves showing the effects of unsaturated BCFA 6a on the viability of MDA-MB-231 and HeLa cancer cells after $48 \mathrm{~h}$ treatment. Data represents the mean \pm SEM of at least 3 independent experiments.

A similar pattern of activity emerged when the BFCAs were tested against MDA-MB231 breast cancer cells. Thus 6a fully abolished cell viability $\left(\mathrm{E}_{\max }=0\right)$ with an $\mathrm{IC}_{50}$ of $534 \pm$ $39 \mu \mathrm{M}$ (Fig. 3) while 13-MTD and the other BCFAs had no effect on cell viability at concentrations up to $900 \mu \mathrm{M}$ (Table S2 in Supplementary Material).

MUFA 6e, the straight-chain analogue of $\mathbf{6 a}$, was also assessed for anticancer activity in all three cell lines (Fig. 4). It was observed that 6e reduced the viability of all cell lines with $\mathrm{IC}_{50}$ concentrations ranging from $86-158 \mu \mathrm{M}$. Comparisons of the $\mathrm{IC}_{50}$ concentrations of $\mathbf{6 a}$ and $\mathbf{6 e}$ in each cell line revealed that $\mathbf{6 a}$ was approximately $1.5-2$ fold more active that its 
unbranched counterpart in MCF-7 and HeLa cells, while in MDA-MB-231 cells 6e was 3.4 fold more active. Viability of MCF-7 cells was fully abolished by $6 \mathbf{e}\left(E_{\max }=0.0\right)$, however $E_{\max }$ values for $\mathbf{6 e}$ against MDA-MB-231 and HeLa cells could not be determined because $\mathbf{6 e}$ was not soluble in cell media at concentrations above $200 \mu \mathrm{M}$.

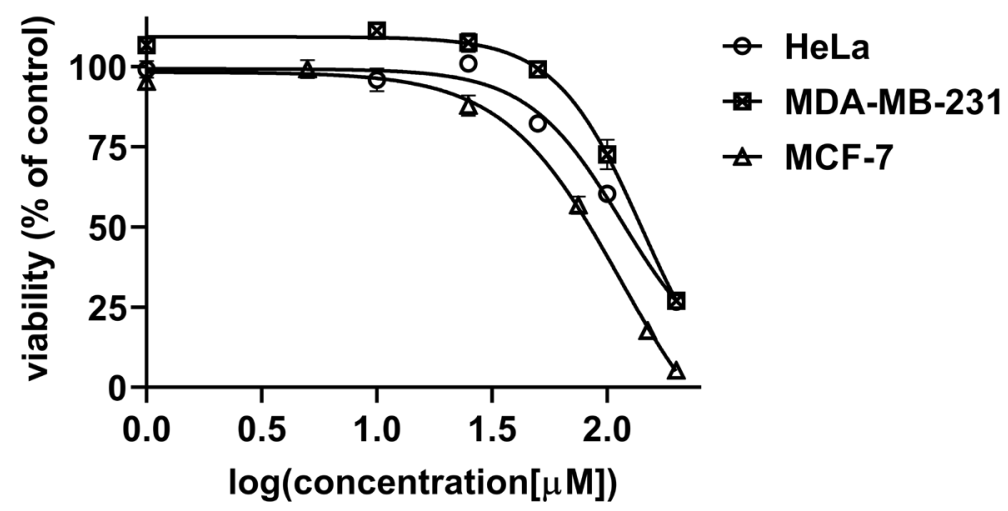

Fig. 4. Dose-response curves showing the effects of MUFA 6e on the viability of MCF-7, MDA-MB-231 and HeLa cancer cells after $48 \mathrm{~h}$ treatment. Data represents the mean \pm SEM of at least 3 independent experiments. 


\section{Discussion}

The development of new anticancer drugs with novel mechanisms of action and low toxicity remains an ongoing need in cancer treatment. BCFAs are structurally distinct from current oncology drugs, well-tolerated in mice and inhibit tumour growth in vivo, and thus present an interesting opportunity for drug development (Murray et al., 2015). The precise cellular target/s of anticancer BCFAs are not known, and medicinal chemistry approaches to improve potency must rely on the synthesis and testing of BCFA analogues, and derivation of an SAR to guide drug design. To date, antiproliferative studies have exclusively examined saturated BCFAs with methyl branching-groups and reported gains in potency have been moderate (Wongtangtintharn et al., 2004). In considering this, we developed two homologous series of BCFAs based on the structure of 13-MTD- one fully saturated series, and a corresponding unsaturated series possessing cis- $\Delta 11$ double bonds- and assessed their anticancer activity against three cancer cell lines.

\subsection{Effects on MCF-7 cell viability}

13-MTD, a widely studied iso-BCFA, inhibits cell growth in various cancer cell lines both in vitro and in vivo (Cai et al., 2013; Lin et al., 2012; Wongtangtintharn et al., 2005; Yang et al., 2000). 13-MTD has previously been reported to reduce MCF-7 cell viability with an $\mathrm{IC}_{50}$ concentrations of $\sim 41 \mu \mathrm{M}$ and $\sim 150 \mu \mathrm{M}$ (Wongtangtintharn et al, 2004), and using the assay conditions developed for this study we found similar levels of cytotoxicity (cf. $\mathrm{IC}_{50} 135 \mu \mathrm{M}$, Table 1). In contrast, 13-MTD was essentially inactive in both MDA-MB-231 and HeLa cells. Within the saturated series, 13-MTD was the only BCFA to significantly affect cellular viability at or below $300 \mu \mathrm{M}$. As the size of the branching group was increased to ethyl $(\mathbf{8 b})$ and propyl (8c) chains, the associated activity decreased (Fig. 2b). Indeed, the butyl-branched 
analogue 8d was inactive at all test concentrations. These findings clearly illustrate a preference for smaller methyl-branching groups in saturated BCFAs.

The unsaturated BCFAs 6a-d were all active and reduced MCF-7 viability. This activity pattern indicates that the activity of unsaturated BCFAs are not as sensitive to branching group size as their saturated counterparts. Interestingly, while 6a-d displayed similar $\mathrm{IC}_{50}$ concentrations, differences in the dose-response curve of butyl-branched $\mathbf{6 d}$ were observed. The HS values for $\mathbf{6 a - d}$ were within the range reported for a wide panel of anticancer drugs against MCF-7 cells (Fallahi-Sichani et al., 2013), however 6d had a relatively low HS and high $E_{\max }$ relative to 6a-c. We saw no evidence that the high $E_{\max }$ value of $\mathbf{6 d}$ resulted from precipitation in the assays. Indeed, similar shallow dose-response curves with $\mathrm{E}_{\max }$ values $>0$ have been reported for the clinical anticancer drugs docetaxel and geldanamycin in cell viability assays using the MCF-7 cell line (Fallahi-Sichani et al., 2013). Thus, the differences in $\mathrm{HS}$ and $\mathrm{E}_{\max }$ values calculated for $\mathbf{6 d}$ suggest that $\mathbf{6 d}$ reduces MCF-7 cell viability by a different mechanism of action to 6a-c (Fallahi-Sichani et al., 2013), which may arise from the increased bulk provided by the butyl branching-group in $\mathbf{6 d}$ causing it to interact with different cellular target/s to that of 6a-c. Follow-up mechanistic studies could assess the ability of $\mathbf{6 a - d}$ to inhibit COX-2 activity as MUFAs with anticancer activity have been shown to reduce COX2 mediated prostaglandin $\mathrm{E}_{2}\left(\mathrm{PGE}_{2}\right)$ synthesis (Cui et al., 2012).

\subsection{Effects on MDA-MB-231 and HeLa cell viability}

13-MTD has been shown to reduce the viability of over 10 cancer cell lines, however the anticancer activity of 13-MTD and other BCFAs has not been studied using MDA-MB-231 and HeLa cancer cell lines. In this study we found that these two cell lines are much more resistant than MCF-7 cells to BCFA anticancer activity. 13-MTD was essentially inactive against both cell lines, and this lack of activity was also observed for all saturated BCFAs (8b- 
d) and unsatutared BCFAs 6b-d. The only exception was the unsaturated and methyl-branched BCFA 6a, which was active across all three cell lines. Comparison of the $\mathrm{IC}_{50}$ concentrations showed that MCF-7 cells were most sensitive to $\mathbf{6 a}$, followed by HeLa and then MDA-MB231 cells. Consistent with this pattern of activity, HeLa cell viability was moderately reduced by the remaining BCFAs at $900 \mu \mathrm{M}$, while MDA-MB-231 cells were unaffected at all test concentrations.

\subsection{Effect of fatty acid branching on anticancer activity-comparison of $\mathbf{6} \boldsymbol{a}$ and $\mathbf{6 e}$}

Cell testing revealed that $\mathbf{6 a}$ is one of the most potent BCFAs reported to date, and almost 3-fold more potent that it's saturated counterpart 13-MTD. Furthermore, within the series 6a was the only BCFA that was active against all cell lines tested. These results indicate that inclusion of a cis- $\Delta 11$ double bond into the BCFA scaffold greatly increases anticancer activity. However an important SAR consideration is whether the superior activity of $6 \mathbf{a}$ is dependent on the both the methyl branching group and the $c i s-\Delta 11$ double bond, or the double bond only, because several straight chain MUFAs have been reported to reduce the viability of breast cancer cell lines (Cui et al., 2012; Miller et al, 2003). We therefore synthesised MUFA $\mathbf{6 e}$, the unbranched analogue of $\mathbf{6 a}$ and compared their activities. In MDA-MB-231 cells, which were largely unaffected by the BCFAs, 6e was more potent than 6a. However in MCF-7 and HeLa cells, the two cell lines that were more susceptible to BCFAs, the $\mathrm{IC}_{50}$ concentrations of 6a was 1.5 - 2 fold lower than that of $\mathbf{6 e}$, which confirmed that both the branching group and cis- $\Delta 11$ double bond are critical to activity in these cell lines. Collectively, these findings indicate that unsaturation is an effective strategy to increase the potency of BCFAs, although the effects are cell line dependant.

\section{Conclusions}


By synthesising a homologous series of saturated and unsaturated BCFAs and evaluating their effects on the viability of MCF-7, MDA-MB-231 and HeLa cells, we have been able to expand the structure-activity relationship governing BCFA anticancer activity. In general MCF-7 cells were the most susceptible to the anticancer actions of the BCFAs tested, followed by HeLa and then MDA-MB-231 cells. It was shown that symmetrically extending the branching chains of saturated BCFAs is detrimental to activity in MCF-7 cells. In contrast, inclusion of a cis- $\Delta 11$ double bond into the BCFA chain improves activity relative to their corresponding fully saturated analogues and unsaturated BCFA 6a was active across all the cell lines tested. These new SAR insights may assist in the development of new and more potent BCFAs as potential anticancer agents. 


\section{Author Contributions}

TR conceived of the study. RR, AR and TR designed experiments, analysed data and wrote the manuscript. RR synthesised the branched fatty acids and AR carried out cell culture and anticancer testing. 


\section{ACKNOWLEDGEMENTS}

This research did not receive any specific grant from funding agencies in the public, commercial, or not-for-profit sectors. 


\section{REFERENCES}

Ainai T., Matsuumi M., Kobayashi Y., 2003. Efficient Total Synthesis of 12-oxo-PDA and OPC-8:0. J. Org. Chem. 68, 7825-7832.

Aro A., Kosmeijer-Schuil T., van de Bovenkamp P., Hulshof P., Zock P., Katan MB., 1998. Analysis of C18:1 cis and trans fatty acid isomers by the combination of gas-liquid chromatography of 4, 4-dimethyloxazoline derivatives and methyl esters. J. Am. Oil. Chem. Soc. 75, 977-985.

Cai Q., Huang H., Qian D., Chen K., Luo J., Tian Y., Lin T., Lin T., 2013. 13methyltetradecanoic acid exhibits anti-tumor activity on T-cell lymphomas in vitro and in vivo by down-regulating p-AKT and activating caspase-3. PLoS One 8, e65308.

Collins P.W., \& Djuric S.W. 1993. Synthesis of therapeutically useful prostaglandin and prostacyclin analogs. Chem. Rev. 93, 1533-1564.

Cui P.H., Rawling T., Bourget K., Kim T., Duke C.C., Doddareddy M.R., Hibbs, D.E., Zhou, F., Tattam, B.N., Petrovic, N., Murray, M., 2012. Antiproliferative and Antimigratory Actions of Synthetic Long Chain n-3 Monounsaturated Fatty Acids in Breast Cancer Cells That Overexpress Cyclooxygenase-2. J. Med. Chem. 55, 7163-7172.

Dejarlais W., Emken, E., 1978. Synthesis of di-, tetra, and hexadeuterated 11-octadecenoates. J. Labelled Comp. Rad. 15, 451-460

Fallahi-Sichani M., Honarnejad S., Heiser L.M., Gray J.W., Sorger P.K., 2013. Metrics other than potency reveal systematic variation in responses to cancer drugs. Nat. Chem. Biol. 9, 708-714.

Foglia T., \& Vail P. 1993. An efficient, large-scale syntheis of triisopentadecanion. Org. Prep. Proced. Int. 25, 209-213.

Ito H., Momose T., Konishi M., Yamada E., Watanabe K., Iguchi K., 2006. Enantioselective total synthesis of both diastereomers of preclavulone-A methyl ester. Tetrahedron 62, 1042510433.

Jana S., Sarpe V., Kulkarni, S., Jana S., 2018. Total Synthesis of Emmyguyacins A and B, Potential Fusion Inhibitors of Influenza Virus. Org. Lett. 20, 6938-6942

Khan A., Kodar K., Timmer M., Stocker, B., 2018. Lipid length and iso-branching of trehalose diesters influences Mincle agonist activity. Tetrahedron. 74, 1269-1277.

Lin T, Yin X, Cai Q, Fan X, Xu K, Huang L, Luo J., Zheng J., Huang J., 2012. 13Methyltetradecanoic acid induces mitochondrial-mediated apoptosis in human bladder cancer cells. Urol. Oncol. 30, 339-345. 
Miller A., McGrath E., Stanton C., Devery R., 2003. Vaccenic acid (t11-18: 1) is converted to c9, t11-CLA in MCF-7 and SW480 cancer cells. Lipids 38, 623-632.

Murray M., Dyari H.R.E., Allison S.E., Rawling T., 2014. Lipid analogues as potential drugs for the regulation of mitochondrial cell death. Br. J. Pharmacol. 171, 2051-2066.

Murray M., Hraiki A., Bebawy M., Pazderka C., Rawling T., 2015. Anti-tumor activities of lipids and lipid analogues and their development as potential anticancer drugs. Pharmacol. Ther. 150, 109-128.

Oku H., Yanagita T., 2009. Branched-Chain Fatty Acid as a Functional Lipid. Biocatal. Agric. Biotechnol. 259-267.

Rawling T., Duke C.C., Cui P.H., Murray M., 2010. Facile and Stereoselective Synthesis of (Z)-15-Octadecenoic Acid and (Z)-16-Nonadecenoic Acid: Monounsaturated Omega-3 Fatty Acids. Lipids 45, 159-165.

Riehm H., Biedler J.L., 1972. Potentiation of Drug Effect by Tween 80 in Chinese Hamster Cells Resistant to Actinomycin and Daunomycin. Cancer Res. 32, 1195-1200.

Shioiri T., Terao Y., Irako N., Aoyama T., 1998. Synthesis of topostins B567 and D654 (WB-3559D, flavolipin), DNA topoisomerase I inhibitors of bacterial origin. Tetrahedron 54, 15701-15710.

Vahmani P., Salazar V., Rolland D.C., Gzyl K.E., Dugan M.E., 2019. Iso-but Not AnteisoBranched Chain Fatty Acids Exert Growth-Inhibiting and Apoptosis-Inducing Effects in MCF-7 Cells. J. Agric. Food Chem. 67, 10042-10047.

van B.W.J., Verheij M., 2013. Anticancer mechanisms and clinical application of alkylphospholipids. Biochim. Biophys. Acta 1831, 663-674.

Wongtangtintharn S., Oku H., Inafuku M., Iwasaki H., Toda T., 2006. Effects of Carbon Chain Structures of Fatty Acids on Their Cytotoxicity to Breast Cancer Cells J. Nut. Food Science 59, 115-118.

Wongtangtintharn S., Oku H., Iwasaki H., Inafuku M., Toda T., Yanagita T., 2005. Incorporation of branched-chain fatty acid into cellular lipids and caspase-independent apoptosis in human breast cancer cell line, SKBR-3. Lipids Health Dis. 4, 29-42.

Wongtangtintharn S., Oku H., Iwasaki H., Toda T., 2004. Effect of branched-chain fatty acids on fatty acid biosynthesis of human breast cancer cells. J. Nutr. Sci. Vitaminol. 50, 137143. 
Wright K.C., Yang P., Van Pelt C.S., Hicks M.E., Collin P., Newman R.A., 2005. Evaluation of targeted arterial delivery of the branched chain fatty acid 12-methyltetradecanoic acid as a novel therapy for solid tumors. J. Exp. Therapeut. Oncol. 5, 55-68.

Wube A., Hüfner A., Thomaschitz C., Blunder M., Kollroser M., Bauer R., Bucar F., 2011. Design, synthesis and antimycobacterial activities of 1-methyl-2-alkenyl-4(1H)-quinolones. Bioorg. Med. Chem. 19, 567-579.

Yang P., Collin P., Madden T., Chan D., Sweeney-Gotsch B., McConkey D., Newman R.A., 2003. Inhibition of proliferation of PC3 cells by the branched-chain fatty acid, 12methyltetradecanoic acid, is associated with inhibition of 5-lipoxygenase. The Prostate 55, 281-291.

Yang Z., Liu S., Chen X., Chen H., Huang M., Zheng J., 2000. Induction of apoptotic cell death and in vivo growth inhibition of human cancer cells by a saturated branched-chain fatty acid, 13-methyltetradecanoic acid. Cancer Res. 60, 505-509. 